\title{
Anomalous circumflex artery arising from the right coronary sinus
}

Hamit Serdar Başbuğ ${ }^{1}$, Ahmet Karakurt², Macit Bitargil ${ }^{1}$, Kanat Özışı1 ${ }^{1}$

Received: January 06, 2016 Accepted: February 28, 2016 Published online: July 21, 2016

Coronary artery anomalies are seen in approximately $6 \%$ of the population. ${ }^{[1]}$ Coronary artery anomalies which originate from the wrong coronary sinus may cause a risk of sudden death in young populations. ${ }^{[2]}$ The incidences of anomalous circumflex artery $(\mathrm{CxA})$ arising from the wrong coronary sinus occur in $0.67 \%$ of the total population. ${ }^{[1]}$ We reported an uncommon anatomical variation of the $\mathrm{CxA}$ which emphasized the anatomic variabilities of the vascular structures.

\section{CASE REPORT}

A 71-year-old male was referred to the Emergency Department with a complaint of angina pectoris. His blood pressure was normal $(130 / 65 \mathrm{mmHg})$ and his heart rate was slightly increased (119 bpm). Troponin-I levels were $15.7 \mathrm{ng} / \mathrm{mL}$ (Normal $<0.01 \mathrm{ng} / \mathrm{mL}$ ) on admission. The electrocardiography revealed an ST elevation in D3 and aVF leads. He was diagnosed with an acute inferior myocardial infarction (AMI) and a

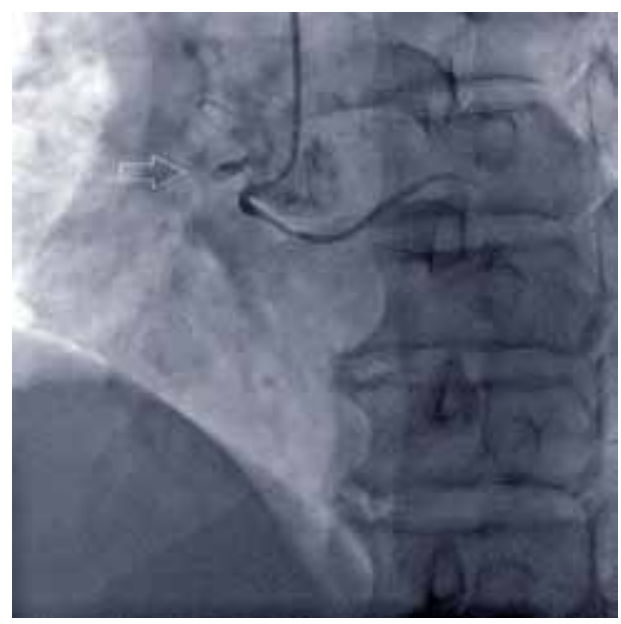

Figure 1. Left anterior oblique view showing the separate orifices of the right coronary artery and the circumflex coronary artery. The arrow showing the right coronary artery stump. coronary angiography was performed to intervene the responsible coronary lesion. A rare anatomic variation was seen on the right coronary vasculature. The $\mathrm{CxA}$ was originating from the right coronary sinus with its own separate ostium (Figure 1). The distal course of the $\mathrm{CxA}$ was normal following the anatomic grooves
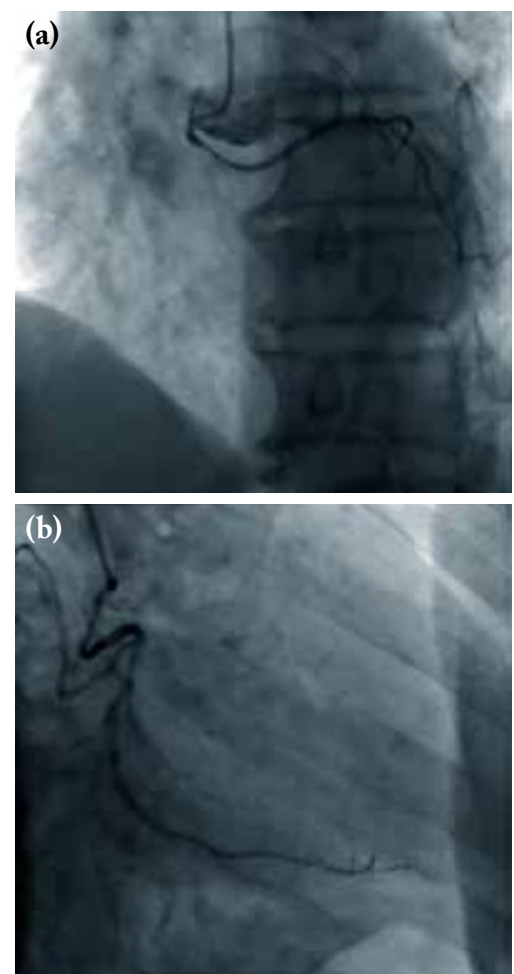

Figure 2. Left anterior oblique (a) and right anterior oblique (b) views of the circumflex artery showing the anomalous origin from the ordinary course.

Departments of ${ }^{1}$ Cardiovascular Surgery, ${ }^{2}$ Cardiology, Medical Faculty of Kafkas University, Kars, Turkey

Corresponding author: Hamit Serdar Başbuğ, MD. Kafkas Üniversitesi Tıp Fakültesi Kalp ve Damar Cerrahisi Anabilim Dal, 36100 Kars, Turkey. Tel: +90 474 - 2251190 e-mail: s_basbug@hotmail.com 


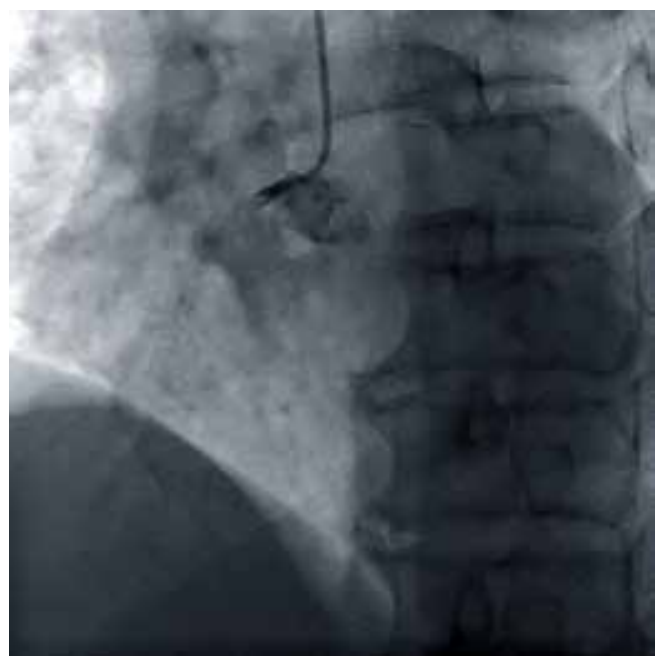

Figure 3. Right coronary artery proximal occlusion stump and the distal silhouette.

(Figure 2). There were some atherosclerotic lesions in the CxA including a $60 \%$ segmental lesion in the proximal portion (Figure $2 \mathrm{a}$ ) and a diffuse endothelial irregularity in the middle portion (Figure 2b). He had a separate right coronary artery orifice with a total proximal occlusion that was responsible for the acute myocardial infarction (Figure 3). The left anterior descending artery was emerging from the left coronary ostium in a typical manner, having no prominent atherosclerotic lesion (Figure 4). A written informed consent was obtained from the patient.

Coronary artery anomalies should be well known regarding the appearance, prevalence and the clinical importance given by the interventionists. ${ }^{[3]}$ The intervention should be adjusted according to the existing coronary artery anomaly.

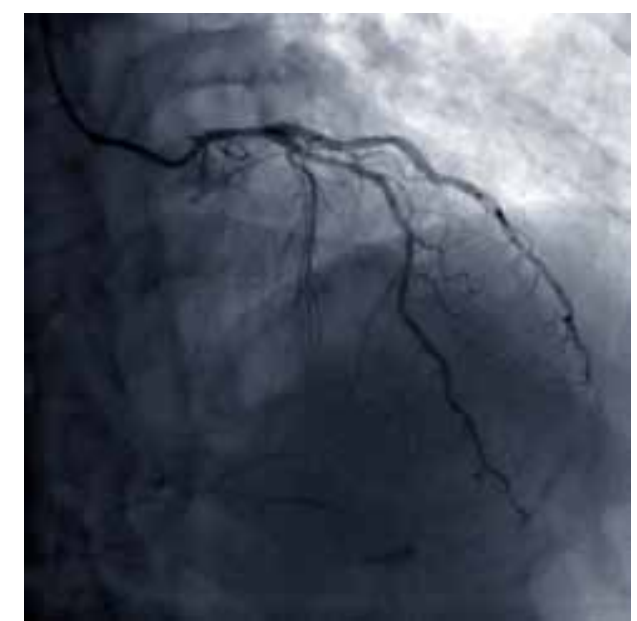

Figure 4. Typical origin and course of the left anterior descending artery and its diagonal branch.

\section{Declaration of conflicting interests}

The authors declared no conflicts of interest with respect to the authorship and/or publication of this article.

\section{Funding}

The authors received no financial support for the research and/or authorship of this article.

\section{REFERENCES}

1. Angelini P. Coronary artery anomalies: an entity in search of an identity. Circulation 2007;115:1296-305.

2. Basso C, Maron BJ, Corrado D, Thiene G. Clinical profile of congenital coronary artery anomalies with origin from the wrong aortic sinus leading to sudden death in young competitive athletes. J Am Coll Cardiol 2000;35:1493-501.

3. Earls JP. Coronary artery anomalies. Tech Vasc Interv Radiol 2006;9:210-7. 